Dr. Antonio Linares Gutiérrez

Abogado, doctor en Derecho, profesor universitario,

DPO certificado

@ alinares@icam.es
Recibido / Received 29 de diciembre de 2018

- Aceptado / Acepted 1 de febrero de 2019

- Páginas / Pages De la 139 a la 147

- ISSN: 2531-0054

\title{
El consentimiento en los contratos telefónicos de prestación de servicios de comunicaciones ante la nueva regulación sobre protección de datos personales
}

Consent in contracts telephone services of communications services before the new regulation on personal data protection

Las compañías de telecomunicaciones recurren cada vez con más frecuencia a campañas comerciales telefónicas con el objeto de ofertar a sus usuarios nuevos productos o para captar nuevos clientes. Sin embargo, se incumple en un alto porcentaje de las ocasiones la obligación de remitir el contrato por escrito al nuevo cliente o de la grabación telefónica a petición de un colegio arbitral u órgano judicial. Ante la inexistencia de contrato escrito o de la grabación del contrato verbal, las empresas vienen recurriendo a la figura del consentimiento tácito a la hora de probar la existencia y validez de un contrato. Esta situación, a la luz de la nueva regulación en materia de protección de datos, va a experimentar una notable transformación al no tener cabida la aplicación del consentimiento tácito para el tratamiento de datos personales. Por este motivo, los operadores de telecomunicaciones deberán reestructurar la forma en la que llevan a cabo su contratación telefónica si no quieren verse expuestos a fuertes sanciones por parte de la Agencia Española de Protección de Datos.

PALABRAS CLAVE: protección de datos personales, consentimiento, consentimiento tácito, contrato telefónico, servicio de telecomunicaciones.

Telephone companies have been increasingly using commercial telephone campaigns in order to offer their customers new products or to attract new customers. However, the obligation to send new customers a written copy of the contract or to record the telephone call, as requested by arbitration colleges and judicial bodies, is often not complied with. In the absence of a written contract or a recording of the verbal contract, companies have been using tacit consent in order to prove the existence of a contract. Due to the application of the new regulation on data protection, this situation will change, as the application of the aforementioned tacit consent is not allowed anymore. For this reason, it will be necessary for telephone 
companies to change the way in which they start contracts over the phone if they want to avoid the risk of receiving heavy sanctions by the Spanish Data Protection Agency.

KEYWORDS: protection of personal data, consent, tacit consent, telephone contract, telecommunication service.

\section{Introducción}

La contratación telefónica, lejos de desaparecer, ha experimentado un fuerte auge en los últimos años. Es habitual recibir llamadas de compañías de telecomunicaciones, empresas eléctricas, suministradoras de gas, etc., ofreciendo unos contratos con unas condiciones muy ventajosas que, además, tan solo podremos acceder a ellas si aceptamos en ese momento. En otras ocasiones, la propia compañía de servicios que tenemos contratada es la que nos ofrece un cambio de tarifa o modificación contractual con unas condiciones realmente inmejorables, sobre todo cuando ha tenido noticia de la intención del consumidor de cambiar de empresa suministradora.

La práctica del telemarketing está muy extendida actualmente y tiene una clara ventaja sobre el resto de las técnicas de venta por llevarse a cabo de forma directa y personal con el cliente. Este extremo, junto con el desarrollo tecnológico en el sector de las comunicaciones y su abaratamiento, hacen que este servicio haya experimentado un crecimiento exponencial. Según estadísticas publicadas por la Asociación de Contact Center Española (ACE, 2017) en el informe «El sector del contact center en España, 2017», el retorno se sitúa en torno al $13 \%$ de media, mientras que en marketing por email, en el 0,12\%, y en el correo directo, entorno al 3,40\%. En este mismo informe se constata el nivel de facturación del sector, fijándose en 1.723,96 millones de euros, dando empleo al cierre de 2016 a 70.525 personas en España, un 3,5\% más que en 2015. También se indica la evolución de negocio: la facturación en el año 2000 ha pasado de $606.740 .000 €$ a los indicados $1.723 .960 .000 €$ en 2016, es decir, prácticamente se ha triplicado el incremento del sector en poco más de quince años. No obstante, las cifras indicadas son notablemente mayores ya que tan solo se recogen las relativas a las empresas que se dedican a esta actividad, y no se contemplan ni los puestos de trabajo ni ingresos que puedan provenir de empresas que realicen esta labor como complemento a su actividad principal.

Sin embargo, los operadores de telecomunicaciones, en un elevado porcentaje de las ocasiones, no cumplen con la regulación aplicable a este tipo de venta «a distancia». El aspecto comercial prioriza sobre el legal, de tal manera que se asume el riesgo de sufrir algún tipo de perjuicio como consecuencia de un incumplimiento legal con tal de aumentar la cifra de ventas. No obstante, esta situación puede cambiar a la vista de la nueva regulación que ha entrado en vigor en materia de protección de datos personales y, más concretamente, en la forma de prestar el consentimiento por parte del consumidor, este es precisamente el objeto del estudio.

\section{El consentimiento tácito del consumidor en la contratación telefónica}

El consentimiento en la contratación celebrada a distancia (en la que se encuentra incluida la telefónica, como así se establece en el artículo 92 del RD 1/2007 Ley General para la De- 
fensa de los Consumidores y Usuarios), está contemplado en nuestro ordenamiento jurídico tanto en el Código Civil (CC), como en normas específicas o sectoriales.

En el CC, además de constituir el consentimiento uno de los tres requisitos esenciales para la existencia de un contrato (art. 1.261), también hace expresa remisión a los contratos celebrados a distancia a través de su artículo 1.262, el cual dispone que «hallándose en lugares distintos el que hizo la oferta y el que la aceptó, hay consentimiento desde que el oferente conoce la aceptación o desde que, habiéndosela remitido el aceptante, no pueda ignorarla sin faltar a la buena fe».

Por su parte, el Real Decreto 899/2009, de 22 de mayo, por el que se aprueba la carta de derechos del usuario de los servicios de comunicaciones electrónicas, en el artículo 5 se hace constar que «la formalización y entrega del contrato se regirá por lo dispuesto en el texto refundido de la Ley General para la Defensa de los Consumidores y Usuarios y otras leyes complementarias, aprobado por el Real Decreto Legislativo 1/2007, de 16 de noviembre». En esta última disposición, en su artículo 62 se establece que «en la contratación con consumidores y usuarios debe constar de forma inequívoca su voluntad de contratar o, en su caso, de poner fin al contrato".

De los preceptos reseñados cabe destacar que no se excluye el consentimiento tácito en los contratos celebrados a distancia. Del CC no se desprende la imposibilidad de prestarse este tipo de consentimiento y la Ley General de Defensa del Consumidor hace constar solamente que el consentimiento debe ser prestado de forma inequívoca, lo cual no es incompatible con consentimiento tácito. Únicamente esta disposición contempla la necesidad de que el consentimiento sea expreso (art. 98.7.b), para un supuesto concreto (pérdida del derecho de desistimiento). Por tanto, cabe concluir que el consentimiento tácito resulta legalmente aplicable en la contratación a distancia con los consumidores. No obstante, en los próximos apartados, se analizará si dicho consentimiento tácito también resulta procedente desde el punto de vista de la protección de los datos personales.

\section{El consentimiento del usuario del servicio de telecomunicaciones en materia de protección de datos personales}

\subsection{La validez del consentimiento tácito en las viejas normas sobre la materia}

Se ha podido constatar que el consentimiento tácito ha sido invocado ante el incumplimiento de la obligación contenida en el artículo 98.7 de la Ley General para la Defensa de los Consumidores y Usuarios (RD Leg. 1/2007, de 16 de noviembre), el cual dispone que:

El empresario deberá facilitar al consumidor y usuario la confirmación del contrato celebrado en un soporte duradero y en un plazo razonable después de la celebración del contrato a distancia, a más tardar en el momento de entrega de los bienes o antes del inicio de la ejecución del servicio. 
La falta de observancia de este precepto ha sido apreciada tras analizar los 1.195 laudos emitidos por la Junta Arbitral de Consumo de la Comunidad de Madrid referidos al sector de las telecomunicaciones y respecto al ejercicio 2015 (último disponible en el portal de transparencia de la Comunidad de Madrid). Evidentemente, no se trata de identificar todos los casos en los que se ha infringido el artículo 98.7 RD 1/ 2007 en España, sino que se pretende analizar una muestra para poder llegar a unas conclusiones que sirvan de referencia. En concreto, han sido consideradas aquellas situaciones en las que la Junta Arbitral requirió a los operadores de telecomunicaciones para que aportasen el documento o la grabación que respaldase un supuesto contrato telefónico. Han sido localizados 142 procedimientos arbitrales en los que se contiene dicho requerimiento, aportándose la grabación en 87 ocasiones (61\%) y sin hacerse en 55 (39\%). Con el objeto de justificar la falta de aportación de las grabaciones, se utilizaron argumentos como que «técnicamente no ha sido posible encontrar la grabación»; «que las grabaciones se llevan a cabo de forma aleatoria»; «en estos momentos no ha sido posible localizar la grabación»; «que no se puede adjuntar copia de la grabación llevada a cabo pues no se dispone de la mismas»; «no ha sido posible su recuperación por razones técnicas»; «las llamadas realizadas al servicio de atención al cliente no se graban en su totalidad, sino que se hace de manera aleatoria» o, simplemente, no se dijo nada. Por otra parte, en siete ocasiones (expedientes 1863, 1890, 2047, 3042, 3063, 3251 y 3741), a pesar de haberse aportado la grabación, no resultó válida, bien sea porque no concretó nada; se interrumpió la respuesta del reclamante; no se aclaró el comienzo del compromiso de permanencia o se aportó una grabación que no era la correcta. Por tanto, las cifras indicadas anteriormente deberán variarse en el sentido de apreciar que de las 142 ocasiones en que se solicitó la grabación se aportó correctamente en 81 (57\%), dejando de hacerse, por tanto, en 61 (43\%). Otra particularidad observada es que, en las ocasiones en que no se remitió la grabación solicitada, tampoco se aportó la preceptiva confirmación del contrato verbal, ni se acreditó su envío al usuario. Es decir, se incumple el artículo 98.7 del RD 1/ 2007 en más de un $40 \%$ de las ocasiones.

Sin embargo, la falta de acreditación de la celebración de un contrato a distancia mediante una grabación o su confirmación no ha conllevado, necesariamente, que se incumpla la regulación en materia de protección de datos personales. Así, ante las ocasiones en que la empresa reclamada, a requerimiento de la Agencia Española de Protección de Datos (AEPD), no ha aportado ni grabación ni justificación del contrato realizado vía telefónica, la figura del consentimiento tácito ha sido el argumento esgrimido de cara a probar la relación contractual y, por tanto, la prestación del consentimiento. Esta posibilidad queda plasmada en resoluciones de la AEPD como la 1085/2015 (PS 610/2014), en la que se hace constar que un consentimiento tácito puede ser apreciado cuando se den elementos indiciarios que lo acrediten. La doctrina de la AEPD respecto a esta apreciación es extensa, destacándose como indicio relevante el abono de las facturas relativas al contrato cuyo consentimiento se niega y su inacción durante el tiempo que fue cliente de la compañía reclamada (PS 393/2013, PS 355/2013, PS 350/2014, PS 99/2015, PS 383/2015 y 170/2018).

Por su parte, la Audiencia Nacional (Sala de lo Contencioso Administrativo) ha conocido con profundidad asuntos referidos al consentimiento prestado de forma tácita en el ámbito de la protección de datos personales. Cabe destacar las sentencias dictadas de fechas 1 de febrero de 2006 (SAN rec. 250/2004), 20 de septiembre de 2006 (SAN rec. 626/2004), 27 de 
febrero de 2008 (SAN rec. 290/2006) y 21 de enero de 2009 (SAN rec. 109/2008). En las mismas, se aprecia la prestación del consentimiento de forma inequívoca y de conformidad con el ya derogado artículo 6.1 de la LOPD (LO 15/1999) al haber sido prestado mediante actos presuntos o por el silencio del afectado (consentimiento tácito). En otras sentencias, como las de fecha 16 de abril de 2009 (SAN rec. 380/2008), 4 de junio de 2009 (SAN rec. 107/2008), 12 de noviembre de 2009 (SAN rec. 684/2008), 3 de marzo de 2011 (SAN rec. 100/2010) y 12 de enero de 2012 (SAN rec. 700/2010), el abono de facturas se entendió como indicio suficiente para considerar prestado el consentimiento de forma tácita. Pero es en la sentencia de fecha 29 de abril de 2010 (SAN rec. 620/2009) donde la laxitud a la hora de apreciar el consentimiento tácito se muestra de forma más evidente. Así, en su Fundamento Jurídico Cuarto se estima como indicio suficiente la existencia de llamadas telefónicas entre dos números determinados. Sin embargo, esta clara predisposición jurisprudencial, a la hora de apreciar la existencia de un consentimiento tácito, choca frontalmente con el requisito de ser apreciado de forma restrictiva, como así queda establecido en la sentencia de la Audiencia Nacional de fecha 7 de julio de 2000, (SAN rec. 121/ 1999) en cuyo Fundamento de Derecho Tercero se hace constar que «este tema del consentimiento tácito ha de ser tratado con una gran delicadeza cuando están en juego derechos constitucionales básicos», para seguir afirmando que deberán tomarse «todas las cautelas normativas tendentes a proteger esa privacidad, sin que quepan interpretaciones de laxitud».

Por tanto, queda fuera de toda duda que, al amparo de la derogada LOPD y su Reglamento de desarrollo (RD 1720/2007), el consentimiento tácito resultaba plenamente aplicable cuando no pudo probarse mediante contrato escrito o grabación del contrato verbal. Mediante esta vía, las empresas, especialmente del sector de las telecomunicaciones, han evitado cuantiosas sanciones por parte de la AEPD.

\subsection{La exigencia del consentimiento expreso en el nuevo marco normativo}

Con la entrada en vigor del Reglamento Europeo sobre Protección de Datos (RGPD UE 2016/679) y de la nueva ley sobre protección de datos (LO 3/2018), la forma de prestar el consentimiento ha sido objeto de importantes novedades. La situación de cierta permisibilidad ante la falta de entrega por parte de la una empresa del contrato o de la grabación telefónica deberá experimentar una radical transformación en virtud de la referida normativa. Cabe decir que la LO 3/ 2018 regula el consentimiento en su artículo 6.1 haciéndose remisión al 4.11 del RGPD, reproduciendo su contenido. Por este motivo, cuando se haga referencia a RGPD, también se hará, de forma implícita, a la LO 3/ 2018. Concretamente, el artículo 4.11 del RGPD establece que:

Artículo 4. Definiciones: A efectos del presente Reglamento se entenderá por:

11) Consentimiento del interesado: toda manifestación de voluntad libre, específica, informada e inequívoca por la que el interesado acepta, ya sea mediante una declaración o una clara acción afirmativa, el tratamiento de datos personales que le conciernen. 
A diferencia de la legislación anterior (LOPD y RD 1720/2007), del RGPD no se desprende la posibilidad del consentimiento tácito. Para llegar a esta conclusión se parte, en primer lugar, del concepto de consentimientos tácito. En este sentido, según la Real Academia Española de la Lengua, por tácito se entiende «callado, silencioso, que no se entiende, percibe, oye o dice formalmente, sino que se infiere». Nuestro Código Civil no recoge una definición de consentimiento, aunque sí lo hacen otros ordenamientos, como el Código Civil mexicano, en cuyo artículo 1.803 se dispone que el consentimiento tácito «resultará de hechos o de actos que lo presupongan o que autoricen a presumirlos».

Es a través de la jurisprudencia donde puede encontrarse una definición de declaración de voluntad tácita. Así, el Tribunal Supremo, en sentencias de fecha 8 de febrero de 1964, 26 de mayo de 1986 y 11 de junio de 1991, en interpretación del artículo 1.253 del CC, se refiere al consentimiento tácito de la siguiente manera:

Existen tres modos o formas básicas del consentimiento: expreso, manifestado mediante un acto positivo y declarativo de la voluntad; tácito, cuando pudiendo manifestar un acto de voluntad contrario, este no se lleva a cabo, es decir, cuando el silencio se presume o se presupone como un acto de aquiescencia o aceptación; y presunto, que no se deduce ni de una declaración ni de un acto de silencio positivo, sino de un comportamiento o conducta que implica aceptación de un determinado compromiso u obligación.

La sentencia del Tribunal Supremo (Sala de lo Civil) de fecha 28 de febrero de 1990 aporta mayores argumentos para poder considerar la existencia de un consentimiento tácito, haciendo constar, en su Fundamento de Derecho Tercero, que:

Las declaraciones de voluntad constitutivas de un negocio jurídico pueden ser expresas o tácitas; la declaración de voluntad es tácita cuando el sujeto no manifiesta de un modo directo su voluntad-generalmente mediante el lenguaje oral o escrito-, sino que realiza una determinada conducta que, por presuponer necesariamente tal voluntad, es valorada por el Ordenamiento jurídico como declaración; se dice entonces que la voluntad se declara por medio de hechos concluyentes (facta concludentia; facta ex quibus voluntas concludi potest).

Por otro lado, la Audiencia Nacional, en sentencias de fechas 1 de febrero de 2006 (SAN rec. 250/2004), 20 de septiembre de 2006 (SAN rec. 626/2004) y 3 de diciembre de 2008 (SAN rec. 509/2007), se ha aplicado como indicio de consentimiento tácito el silencio o la inacción del interesado, aplicándose, de hecho, el latinismo qui tacet, consentire videtur (quien calla otorga), impropiamente llamado silencio positivo (SSAN de 27 de febrero de 2008 y 21 de enero de 2009, entre otras). De la jurisprudencia referida, cabe destacar, a efectos del presente estudio, el silencio y la necesidad de su valoración por el ordenamiento jurídico, como principales características del consentimiento tácito.

Una vez delimitados los elementos que configuran el consentimiento tácito, procede determinar si puede seguir siendo aplicable tras la publicación del RGPD y LOPDGDD. En este sentido, y tal y como se ha expuesto, el RGPD en su artículo 4.11 requiere que el consenti- 
miento sea «libre, específico, informado e inequívoco, y prestado mediante una declaración o una clara acción afirmativa». Por su parte, el artículo 3 de la derogada LOPD define el consentimiento del interesado como «toda manifestación de voluntad, libre, inequívoca, específica e informada, mediante la que el interesado consienta el tratamiento de datos personales que le conciernen». Entre ambas definiciones se observa que la diferencia radica en que el RGPD, además de los requisitos recogidos en la LOPD, exige que el consentimiento sea prestado «mediante una declaración o una clara acción afirmativa». Esta nueva redacción es la que lleva a considerar la imposibilidad de que el RGPD contemple el consentimiento tácito, ya sea por silencio o inacción. Debe resaltarse que no solo se utiliza la expresión "acción afirmativa», que por sí sola imposibilita la aplicación del consentimiento tácito, sino que también introduce el adjetivo «clara» con el objeto de destacar dicha acción afirmativa. Además, según reiterada jurisprudencia como las sentencias del Tribunal Supremo de fechas 23 de octubre de 2008 (STS rec. 1332/2008), 26 de noviembre de 2010 (STS 808/2010), 5 de noviembre de 2008 (STS 993/2008), 5 de julio de 2011 (STS 465/2011), 26 de noviembre de 2010 (STS 808/2010) y 16 de julio de 2009 (STS 564/2009), entre otras, el consentimiento tácito debe ser objeto de valoración por parte de un órgano judicial. Esta situación se aleja radicalmente de la necesidad de que la acción afirmativa debe ser clara, es decir, que no dé lugar a interpretaciones. Tampoco el pago de unas facturas podrá considerarse como una clara acción afirmativa que pruebe la prestación del consentimiento, ya que su pago puede deberse a no ser incorporado a un fichero de morosidad, por ejemplo. Por otro lado, el silencio del usuario ya no deberá ser considerado como indicio del consentimiento tácito. En el Considerando 32 del RGPD se hace constar que «el silencio, las casillas ya marcadas o la inacción no deben constituir consentimiento».

En definitiva, teniendo en cuenta que el consentimiento debe prestarse mediante una declaración o clara acción afirmativa y sin que pueda ser considerado el silencio o la inacción del interesado, ya no tiene cabida la figura del consentimiento tácito en la nueva regulación sobre protección de datos personales. Sin embargo, nada obsta para que pueda ser apreciado un consentimiento tácito de cara a la perfección un contrato en el puro ámbito civil, y, sin embargo, no para el correcto tratamiento de los datos personales.

A nadie se le escapa la gran dificultad que supondrá para las empresas probar el consentimiento de sus clientes prestado telefónicamente. Tal y como se ha venido exponiendo, a través de los laudos emitidos por la Junta Arbitral de Consumo de la Comunidad de Madrid o en las sentencias dictadas por la AN, queda patente que casi en la mitad de los contratos celebrados telefónicamente estos no han sido grabados y tampoco fueron remitidos por escrito o en soporte duradero a los clientes. Sin embargo, entendemos que esta circunstancia no debe dar cobertura al incumplimiento legal de la necesidad de obtener y acreditar dicho consentimiento. Al fin y al cabo, el tratamiento de los datos sin el consentimiento del interesado supone un tratamiento ilícito a tenor de lo establecido en el artículo 6 del RGPD y es a la empresa a quien le corresponde probar el cumplimiento legal (Considerando 42 RGPD).

\section{Conclusiones}

La contratación telefónica por parte de las compañías de telecomunicaciones ha experimentado un fuerte auge convirtiéndose en una práctica cada vez más habitual. 
1. Las operadoras de telefonía, en más de un $40 \%$ de las ocasiones, no aportan, a petición de los colegios arbitrales de consumo, justificación del contrato celebrado a distancia ni la oportuna grabación.

2. El consentimiento tácito para el tratamiento de los datos personales ha sido estimado tanto por la AEPD como por la jurisprudencia como un consentimiento valido.

3. Con la aplicación del RGPD y la LO 3/2018, el consentimiento tácito para el tratamiento de datos personales ya no tiene cabida.

4. Cabe la posibilidad de que un contrato se haya perfeccionado mediante un consentimiento tácito y, sin embargo, dicho consentimientos no resulte válido para el tratamiento de los datos personales.

5. Las empresas que contraten por teléfono deberán revisar sus procesos de contratación y poder demostrar la prestación del consentimiento de una forma inequívoca mediante una declaración o una clara acción afirmativa. Esta adaptación supondrá realizar una estimable inversión económica, así como superar serias dificultades técnicas, pero, teniendo en cuenta las fuertes sanciones a las que se exponen por parte de la AEPD, no les quedará otra alternativa.

\section{Bibliografía}

ACE 2017, Asociación de Contact Center Española, «El sector del contact center en España, 2017», recuperado de http://www.ace.adigital.org/estudios/estudio_ace_2017.pdf.

Junta Arbitral de Consumo de la Comunidad de Madrid, Portal de Transparencia, laudos emitidos en 2015 referidos al sector de las telecomunicaciones, disponible en http://www.madrid.org/ cs/Satellite?c=Page\&childpagename=PortalConsumidor\%2FPage\%2FPTCS_contenido\&ci$\mathrm{d}=1354665766095$ \&pagename=PTCS_wrapper.

Real Decreto 899/2009, de 22 de mayo, por el que se aprueba la carta de derechos del usuario de los servicios de comunicaciones electrónicas. BOE n.ำ131, de 30 de mayo de 2009.

Real Decreto Legislativo 1/2007, de 16 de noviembre, por el que se aprueba el texto refundido de la Ley General para la Defensa de los Consumidores y Usuarios y otras leyes complementarias. BOE n.으. 287, de 30 de noviembre de 2007.

PS 610/2014, procedimiento sancionador disponible en https://www.aepd.es/resoluciones/PS-006102014_ORI.pdf.

PS 393/2013, procedimiento sancionador disponible en https://www.aepd.es/resoluciones/PS-003932013_ORI.pdf

PS 355/2013, procedimiento sancionador disponible en https://www.aepd.es/resoluciones/PS-003552013_ORI.pdf.

PS 350/2014, procedimiento sancionador disponible en https://www.aepd.es/resoluciones/PS-003502014_ORI.pdf.

PS 99/2015, procedimiento sancionador disponible https://www.aepd.es/resoluciones/PS-00099-2015_ ORI.pdf.

PS 383/2015, procedimiento sancionador disponible en https://www.aepd.es/resoluciones/PS-003832015_ORI.pdf

PS 170/2018, procedimiento sancionador AEPD, disponible en https://www.aepd.es/resoluciones/PS00170-2018_ORI.pdf

SAN rec. 250/2004, Sentencia de la Audiencia Nacional, Sala de lo Contencioso Administrativo, Sección 1. ${ }^{a}$, de 1 de febrero de 2006. Ponente: Guerrero Zaplana, José.

SAN rec. 626/2004, Sentencia de la Audiencia Nacional, Sala de lo Contencioso Administrativo, Sección 1. ${ }^{a}$, de 20 de septiembre de 2006. Ponente: Fernández García, José Arturo. 
SAN rec. 290/2006, Sentencia de la Audiencia Nacional, Sala de lo Contencioso Administrativo, Sección 1. a , de 27 de febrero de 2008. Ponente: Buisán García, María Nieves.

SAN rec. 109/2008, Sentencia de la Audiencia Nacional, Sala de lo Contencioso Administrativo, Sección 1. a , de 21 de enero de 2009. Ponente: Buisán García, María Nieves.

LO 15/1999, LOPD, Ley Orgánica 15/1999, de 13 de diciembre, de Protección de Datos de Carácter Personal, BOE n.을 298, de 14 de diciembre de 1999.

SAN rec. 380/2008, Sentencia de la Audiencia Nacional, Sala de lo Contencioso Administrativo, Sección 1. a , de 16 de abril de 2009. Ponente: Buisán García, María Nieves.

SAN rec. 107/2008, Sentencia de la Audiencia Nacional, Sala de lo Contencioso Administrativo, Sección 1. a , de 4 de junio de 2009. Ponente: Sanz Calvo, María Luz Lourdes.

SAN rec. 684/2008, Sentencia de la Audiencia Nacional, Sala de lo Contencioso Administrativo, Sección 1. ${ }^{a}$, de 12 de noviembre de 2012. Ponente: Sanz Calvo, María Luz Lourdes.

SAN rec. 100/2010, Sentencia de la Audiencia Nacional, Sala de lo Contencioso Administrativo, Sección 1. ${ }^{a}$, de 3 de marzo de 2011. Ponente: Córdoba Castroverde, Diego.

SAN rec. 700/2010, Sentencia de la Audiencia Nacional, Sala de lo Contencioso Administrativo, Sección 1. a $^{\text {, de }} 12$ de enero de 2012. Ponente: Sanz Calvo, María Luz Lourdes.

SAN rec. 620/2009, Sentencia de la Audiencia Nacional, Sala de lo Contencioso Administrativo, Sección 1. ${ }^{a}$, de 29 de abril de 2010. Ponente: Guerrero Zaplana, José.

SAN rec. 121/ 1999, Sentencia de la Audiencia Nacional, Sala de lo Contencioso Administrativo, Sección 1. a , de 7 de julio de 2000. Ponente: Roldán Herrero, Alfredo.

CCF, Código Civil Federal. Publicado en el Diario Oficial de la Federación en 1928, México.

RD 1720/2007, Real Decreto 1720/2007, de 21 de diciembre, por el que se aprueba el Reglamento de desarrollo de la Ley Orgánica 15/1999, de 13 de diciembre, de protección de datos de carácter personal. BOE n.ำ 17, de 19 de enero de 2008.

RGPD UE 2016/679, Reglamento (UE) 2016/679 del Parlamento Europeo y del Consejo, de 27 de abril de 2016, relativo a la protección de las personas físicas en lo que respecta al tratamiento de datos personales y a la libre circulación de estos datos y por el que se deroga la Directiva 95/46/CE. DOUE de 4 de mayo de 2016.

LO 3/ 2018, Ley Orgánica 3/2018, de 5 de diciembre, de Protección de Datos Personales y garantía de los derechos digitales. BOE n.․ 294, de 6 de diciembre de 2018.

STS 808/2010, Sentencia del Tribunal Supremo, Sala Primera de lo Civil, recurso 2401/2005. Ponente: Xiol Ríos, Juan Antonio.

STS rec. 1332/2003, Sentencia del Tribunal Supremo, Sala de lo Civil, de 23 de octubre de 2008. Ponente: García Varela, Román.

STS 993/2008, Sentencia del Tribunal Supremo, Sala de lo Civil, de 5 de noviembre de 2008. Ponente: García Varela, Román.

STS 465/2011, Sentencia del Tribunal Supremo, Sala de lo Civil, de 5 de julio de 2011. Ponente: García Varela, Román.

STS 808/2010, Sentencia del Tribunal Supremo, Sala de lo Civil, de 26 de noviembre de 2010. Ponente: Xiol Ríos, Juan Antonio.

STS 564/2009, Sentencia del Tribunal Supremo, Sala de lo Civil, de 16 de julio de 2009. Ponente: Sierra Gil de la Cuesta, Ignacio.

SAN rec. 250/2004, Sentencia de la Audiencia Nacional, Sala de lo Contencioso Administrativo, Sección 1. a , de 1 de febrero de 2006. Ponente: Guerrero Zaplana, José.

SAN rec. 626/2004, Sentencia de la Audiencia Nacional, Sala de lo Contencioso Administrativo, Sección 1. - , de 20 de septiembre de 2006. Ponente: Fernández García, José Arturo.

SAN rec. 509/2007, Sentencia de la Audiencia Nacional, Sala de lo Contencioso Administrativo, Sección 1. a , de 3 de diciembre de 2008. Ponente: Buisán García, María Nieves. 